\title{
Is Sexual Assault Well Managed in the UK? Can the UK and the US Learn from Each Other?
}

\section{Lucy Love*}

Clinical Director, G4s Forensic \& Medical Service, UK

\begin{abstract}
There are major differences in the management of sexual assault in the US and the UK. The professionals and their training to enable them to conduct these sexual assault examinations differ radically between the two countries and even the definition of what constitutes rape is not the same. The setting for these examinations is also different and using UK data from 12 different counties, the advantages and disadvantages of the UK system are explored.
\end{abstract}

Keywords: Sexual offences; Forensic examination; Victims

Aim: To compare the quantity and quality of doctor and nurse sexual assault examinations within the UK.

\section{Introduction}

Historically both the UK and the majority of US states follow an adversarial system of justice, with evidence being tested "beyond reasonable doubt" and a trial by jury. However the US and the UK have developed their services very differently when managing rape victims, although the goals of a successful prosecution are shared. In this paper, I will explore what the similarities and differences are between the US and the UK systems and whether we can learn from each other to enhance the service given to rape victims.

\section{The UK system and how it differs from the US: historical perspectives}

What constitutes rape in the US and the UK? : There is no one universal definition of rape in the US; instead each state has its own definition. In the UK, the Sexual Offences Act (2003) [1], which covers England, Wales, Scotland and Northern Ireland defines rape as "Person A intentionally penetrates the vagina, anus or mouth of another person $\mathrm{B}$, with his penis; $\mathrm{B}$ does not consent to the penetration and A does not reasonably believe that B consents." A new offence of "assault by penetration" is defined as penetration with an object or part of the body, including a digit to the vagina or anus.

The professionals and their training: There are other major differences between the UK and the US systems. The first involves the professionals carrying out these examinations. In the UK the examination of rape victims has been DOCTOR- led rather than NURSE- led as it is in the US. The UK system developed from the tradition of the male police surgeon, who Practitioner was a General [G.P], being contracted by the local police service to attend to the medical needs of detained persons in custody and in addition they were expected to collect forensic evidence in rape cases. These forensic examinations were traditionally carried out in a "Vulnerable Victim Suite", which consisted of a basic examination room attached to a Police Station. The forensic and medical needs of the victim were meant to be met by this one male doctor who was not a specialist in sexual assault, might not even be sympathetic or non-judgemental and could offer no crisis support, counseling, emergency contraception or HIV PEP and would have to refer the victim on for these requirements. Since the new Sexual Offences Act (2003) and the setting up of the Havens Sexual Assault Referral Centres (SARCs) in London and the St
Mary's Manchester SARC, the situation has started to improve, but has developed differently from the US system.

The service in the UK has always been doctor led and so the training has revolved around traditional medical learning methods leading to examinations, such as the Membership Exam for the Faculty of Forensic and Legal medicine or the Diploma in Medical Jurisprudence. These exams were theory based rather than practical competencies and involved substantial personal expense to the doctor with a huge time commitment. As a consequence, few doctors have these qualifications and the training received is at the best patchy and often totally inadequate. In many area of the UK, these sensitive examinations of traumatized victims are still undertaken by male doctors, often from abroad with no specialist training and poor English language skills. All this, however is set to change, with the re-shuffling of the NHS by David Cameron's government, SARC services will now be commissioned by Health -NHS England [2] with only a minor input from the Police. Also, the advent of a new competency based exam, soon to become compulsory-the Diploma in the Forensic and Clinical Aspects of Sexual Assault [DFCASA], which is open to nurses as well as doctors, will ensure that a improving but there is still a postcode specialist workforce dedicated to working with rape victims will be recruited. So, the situation in the UK is lottery. Until very recently, the vast majority of rape examinations in the U.K have been carried out by doctors alone, but forensic nurses are being trained in a few areas of the UK [3], with g4s forensic and medical services being the leading provider of such nurse competency based training. There are one or two postgraduate University courses that offer to nurses a Certificate in Forensic Medicine after 1 year of study or a Masters Degree after 3 years. However, places are limited, the training is expensive and sponsorship may be required. Very gradually, the idea of forensic Nurse Examiners [FNEs] is becoming more acceptable in the UK but many county police forces still reject the idea of nurse examiners and are adamant that nurses could never provide expert testimony in

*Corresponding author: Lucy Love, Clinical Director, G4s Forensic \& Medica Service, UK, E-mail: Ifclove@yahoo.com

Received July 23, 2013; Accepted August 21, 2013; Published August 27, 2013

Citation: Love L (2013) Is Sexual Assault Well Managed in the UK? Can the UK and the US Learn from Each Other? J Forensic Res 4: 191. doi:10.4172/21577145.1000191

Copyright: (C) 2013 Love L. This is an open-access article distributed under the terms of the Creative Commons Attribution License, which permits unrestricted use, distribution, and reproduction in any medium, provided the original author and source are credited. 
Citation: Love L (2013) Is Sexual Assault Well Managed in the UK? Can the UK and the US Learn from Each Other? J Forensic Res 4: 191. doi:10.4172/2157-7145.1000191

Page 2 of 3

court, so convincing the Police Authorities and the Crown Prosecution Service (CPS) to accept nurses will be an uphill struggle.

Location and SARCS: The second major difference between the US and the UK handling of rape victims is the location of these examinations. In the US, examinations were traditionally carried out in the Emergency Room [ER] of a general hospital, whereas in the UK, they took place in Police Stations. In the UK, the situation is slowly changing and with Department of Health [DOH] government initiatives and set up grants, especially dedicated Sexual Assault Referral Centres [SARCs] have been developed. These vary according to their exact locations. Some are situated close to but separate from a police station. Others are located within a sexual health clinic or entirely separate in a quiet out of town either residential or non-residential location. Wherever they are they have to reach certain minimum standards. These standards were set by the Department of Health (DOH) in 2009 [4] and define a SARC as "a highly skilled, one stop destination in the aftermath of a rape or sexual assault and they provide services that are tailored to the needs of victims and underpinned by principles of dignity, respect and belief". The minimum standards for a SARC set by the $\mathrm{DOH}$ include:

i. 24 hour access.

ii. Appropriately trained crisis workers to provide immediate support to victims.

iii. Access to appropriately trained Forensic Physicians (FP's), who are experienced in sexual offences examinations of adults and children.

iv. Choice of gender of physician, where possible.

v. Dedicated, forensically approved and forensically cleanable premises.

vi. A risk assessment for self-harm and safeguarding to be included in the medical consultation with immediate access provided in the SARC to Emergency Contraception and HIV PEP.

vii. Access to support and advocacy through an ISVA (Independent Sexual Violence Advisor) with ongoing support by an ISVA throughout the criminal justice process.

viii. The SARC team to include a SARC Manager and a Clinical Director to oversee the training, clinical governance and quality of forensic examiners.

Recent changes within the UK: The U.K has developed its own way of managing sexual assault with the aspiration of a SARC for every police force or region but the UK has also learnt much from observing the US and the idea of nurse examiners, which 10 years ago in the UK would have seemed impossibility is gradually becoming a plausible option (Table 1).

\section{Method}

Data from a leading private provider of forensic medical services in the UK (G4S FORENSIC AND MEDICAL SERVICES) was examined. This data was collected from 12 different counties within the UK and covered the period April 2012 to April 2013. The total number of sexual offence examinations, undertaken in these 12 counties was recorded and the number of those that were performed by doctors in comparison to the number carried out by nurses was documented. The satisfaction/ dissatisfaction rates for doctor and nurse examinations, as measured by the number of complaints received from victims, crisis workers and police officers following forensic examinations, were compared for doctors and nurses. Feed- back forms giving the opportunity for positive and negative comments were given to victims in all 12 areas and collection of these was attempted but the numbers completed and returned to the SARC staff was too small for any meaningful comparison to be made.

\section{Results}

The total number of rape examinations carried out between April 2012 and April 2013 were 1,462 with 1266 [92.5\%] being carried out by doctors and 196 [7.5\%] by nurses. The percentage of rape examinations carried out by nurses was very small [7.5\%] in comparison to the $92.5 \%$ of rape examinations being carried out by doctors. The number of complaints leading to a Clinical Incident Positive Intervention form [CIPI] being completed for this same time period was 29 with 27 [93.2\%] being complaints against doctors versus 2 [6.8\%] being complaints against nurses. (These numbers are too small to be statistically significant).

\section{Discussion}

The numbers of forensic examinations being completed by nurses in the UK are still very small but complaints against nurses were recorded in 2 out of 196 examinations [1\%] in comparison to the 27 complaints recorded in the 1266 doctor examinations [2\%]. These figures although small and not statistically significant would suggest that there were twice the number of complaints against doctors as there were against nurses, and the satisfaction rate for nurse examinations was double that for doctor examinations. The training of nurses to carry out forensic examinations of rape victims is an exciting new development in the UK; where this is being done, the results, as seen by my data are encouraging, with mainly positive feedback being received about nurses; for example the manager of a SARC when overseeing a nurse examiner for the first time, wrote" This nurse was absolutely excellent with the client and we look forward to working with her again". The model in the UK is unlikely to be nurse-lead only but mixed SARC teams are proposed where nurses will be led by a smaller team
UK

1. Doctor led training. Exams

2. Examination in SARC (Sexual Assault Referral Centre)

3. Police referral as the main route of referral

4. Aftercare e.g. emergency contraception, HIV PEP, integrated within SARC

5. Examination by doctors. Mostly male

6. Support in SARC by specially trained crisis workers

7. Support after examination by ISVA (Independent sexual violence advisor)

8. Evidence in court given by doctors

9. Children examined by doctor and paediatrician
US

Nurse led training. E-Learning

Examination in hospital of community i.e. medical setting Self referral or police referral

Aftercare referred in most cases offsite for emergency contraception, HIV PEP

Examination by nurses. Mostly female

Support by SANE (Sexual assault nurse examiners)

Support after examination by referral on to rape crisis organisation

Evidence in court given by nurses

Children examined by specialist paediatric sexual assault nurse examiner

Data from UK: A comparison of nurse and doctor examinations

Table 1: Management of sexual assault. 
Citation: Love L (2013) Is Sexual Assault Well Managed in the UK? Can the UK and the US Learn from Each Other? J Forensic Res 4: 191. doi:10.4172/2157-7145.1000191

Page 3 of 3

of experienced, highly qualified doctors who can give specialist advice, review notes, statements and colposcopy images and assist with expert advice and opinion evidence for court. More feedback from victims is urgently needed and further work is also required to establish when is the best time to introduce a feedback form to a victim, how many and which questions to ask and who the best staff are to collect this data-should it be the crisis worker shortly after the examination or the independent sexual violence advisor [ISVA], longer after the assault or should the form be just posted out by SARC staff? On-line completion of feedback forms has been encouraged but so far this method has not proved fruitful.

Forensic nurse examiners in the UK could provide some advantages over doctors, including:

i. Gender: Most of the nurses in the UK training to be forensic examiners are female and research has shown that the majority of rape victims, both male and female prefer a female examiner, whereas in the UK, the majority of doctors undertaking sexual offence examinations are male.

ii. Training: At present in the UK, there is no compulsory training for doctors undertaking forensic examinations and training is patchy and often poor, whereas the nurse model of training involves competency based assessments and reflective practice.

iii. Skill set: Nurses by virtue of their training and self-selection tend to be sensitive, empathetic, non-judgemental, good communicators and excellent at following instructions and accurately completing medical records, whereas some of these skills may be lacking in doctors in the UK, particularly those who have recently joined the medical workforce from abroad.

\section{Conclusion}

The UK has learnt much from the US with the nurse model of forensic medical examiners and perhaps the US can now learn from the
UK with centralized commissioning by Health of standardized, high quality, cost-effective services through the provision of SARCS with crisis workers, ISVA'S and immediate on-site aftercare for every region of the country. The ideal model would seem to be the appointment of one or two very experienced female doctors as the Clinical Directors for a SARC, overseeing the quality and training needs of SANEs who would carry out the majority of forensic examinations, whilst leaving the Clinical Director to provide expert advice and to assist in complex cases such as those involving children. This is the proposed model for some areas of the UK and incorporates the US model of nurse examiners into the UK system of doctors. The UK model of a SARC where minimal standards must be met, with the provision of crisis workers, ISVA's and aftercare, so providing high quality care for victims, wherever they live, is a model that could possibly be incorporated into the US SANE model, to ensure high standards of victim care are delivered throughout the US. The provision of ISVAs and Crisis workers is an integral part of a UK SARC and is something that could be embraced by the US, as however well trained a SANE is, they cannot be expected to attend to all the needs of the victim-being sensitive to the emotional needs of the victim whilst conducting a thorough forensic examination, undertaking photo documentation with a colposcope and arranging aftercare, can be just too much for one individual to juggle alone.

I would like to feel that the relationship between the US and the UK is one of symbiosis - we learn from each other to the mutual benefit of both- not purely parasitic with the UK copying the US SANE system.

\section{References}

1. The Sexual Offences Act (2003).

2. (2013) Securing excellence in commissioning sexual assault services. NHS England.

3. (2011) G4S Practical Induction Training for Nurse Sexual Offences.

4. (2003) Revised National Service Guide: A resource for developing sexual assault referral centres. Department of Health. 